\title{
A COMMUNITY OF PRACTICE FOR ACCELERATING THE ADOPTION OF INFORMATION TECHNOLOGY IN ENGINEERING EDUCATION
}

\author{
Forgues, D; Doré S*; Francoeur, É.**; Boland J F***; Laberge V \\ Department of Construction Engineering, École de technologie supérieure (ETS), Montréal, Canada \\ daniel.forgues@etsmtl.ca
}

\section{INTRODUCTION}

The integration of information technology (IT) in teaching activities is often a daunting task for university teaching staff. A new technology means not only having to learn how to use it, but also having to adjust one's teaching practices. Not surprisingly, studies show that teachers hesitate to get involved with new technologies, especially if there is no support structure or special incentives to adopt and use it $[1,2]$.

In this paper, we present a new approach used at the École de technologie supérieure (ETS) to accelerate the adoption of IT in teaching, using a social learning approach based on situated action theories [3].

\section{THE INSTITUTIONAL SETTING}

Routine IT currently available for teaching at ETS includes standard websites, e-mail and classroom equipment such as computers and projectors. State-of-the-art a few years ago, this suite of resources now pales in comparison with what is available in many comparable institutions in Quebec and Canada.

From roughly 2002 to 2008, a number of isolated (and sometimes duplicate) efforts have been made by members of the teaching staff to experiment with various new IT. These efforts met with limited success in terms of the diffusion and wider adoption of these technologies in the institution. Institutional support structure (particularly in the form of user training and support) also failed to materialize.

It was in this context that in 2008 a core group of early adopters (including the authors) came together to bring these bottom-up, user-led initiatives to the next step by developing resources for the wider adoption and use of these technologies in the institution through the community of practice approach. Thus was born the Community of practice on the use of IT in teaching, or C-UTILE, from its French acronym.

\section{THE CAPTURE OF EMERGING KNOWLEDGE AND THE} CREATION OF NEW KNOWLEDGE

From the start, the community has elected to focus on technologies of direct interest to its members. Thus far C-UTILE has focused on five technologies: intelligent boards, audience response systems, community-based tools for learning (Moodle), cloud based systems for collaborative work (Google Apps) and conceptual mapping (Cmap Tools).

The review of the literature on the targeted technologies has revealed that there is in fact very little research being done on their use in education. A vast majority of the literature consists of case studies documenting various attempts at introducing these technologies in the classroom. While these are helpful in identifying potential problems and errors and in illustrating the variety of roles these technologies can play, there is an obvious lack of research specifically addressing the benefits and drawbacks of using these technologies in various classroom settings, according to different learning paradigms (the positivist vs. the socioconstructivist approach, for example). There is also a lack of research on the various approaches that can be used to encourage the diffusion and adoption of these technologies in academic institutions.

The community's main activity is an ongoing action research project which aims at capturing emerging knowledge and creating new knowledge about the targeted technologies. For each technology, a literature review and interviews with super users in various academic institutions are conducted to capture state-of-the-art knowledge and practices. These super users are then convened in focus groups where the "why" and the "how" of the use of these technologies is further discussed. This knowledge is integrated in a knowledge portal whose content is aimed at guiding users in the use of the technologies. The portal also allows the capture of knowledge and experience emerging in the field, thus creating a feedback loop. Another element is the creation of a design laboratory to promote exchanges between teachers and experimentation with various techniques and approaches. A survey of the teaching personnel and students to measure their interest and maturity in the use of these technologies was also conducted. More conventional activities are the organizing of brown bag conferences where speakers are invited to share their IT experience with the wider community, and short introductory courses on using specific technologies.

\section{DISCUSSION}

The community's approach to knowledge capture and creation has so far proven fruitful, leading to a well-structured knowledge database. Only a prototype of the knowledge portal, based on MS SharePoint and OneNote technologies, has been created so far, as a proof of concept (see figure 1). The current consensus is that this portal, to be truly effective, should be built on a more flexible OS independent platform. This is part of the C-UTILE program for next year.

The survey of the teaching staff and students has confirmed that the use of most of the ITs targeted by this project is still very marginal. Lack of training on the use of these technologies was the main grievance of the teaching staff (even of those who actually used the technologies). This is what led C-UTILE to offer, for example, a short "live" introductory course on Moodle, an e-learning platform used in an ad hoc fashion for many years by several C-UTILE members, and which has only recently become officially supported by ETS IT services.

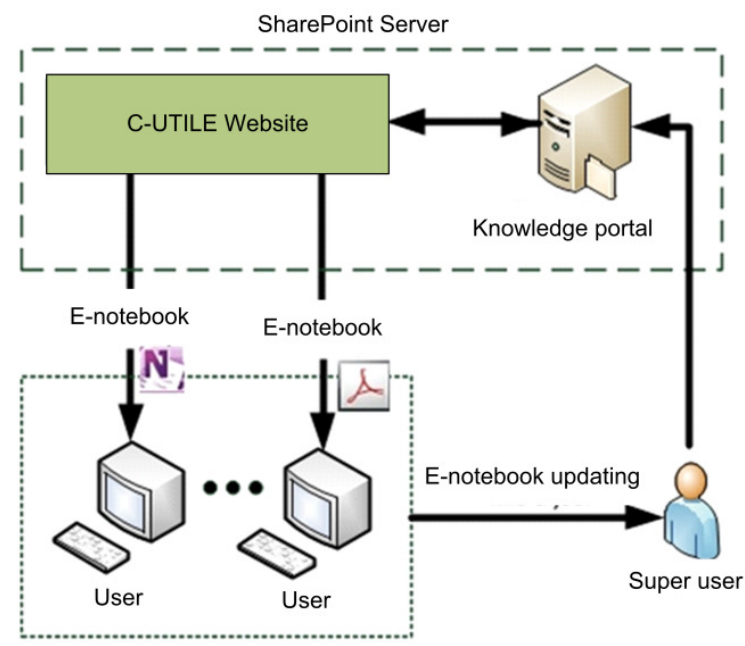

Figure 1: Knowledge Portal Topology

The brown bag conferences have met with great success. Most have attracted wide audiences, generated helpful discussions and helped spark interest in the technology presented -- a reminder that even in the age of IT, "face-to-face" interactions still have their place.

C-UTILE'S ongoing action research project is the first step in the formalization of a process of knowledge building and sharing based on group learning. A "grassroots" initiative from users seeking to break their isolation and the inertia of institutional structures in the face of technological change, this project demonstrates the potential of the community of practice approach to help university teaching staff to regain the ability to shape their educational space.

\section{REFERENCES}

1. Cuthell J. Proceedings of SITE 2003; 2740-44.

2. Osborne $J$ and Hennessy S. Literature Review in Science Education and the Role of ICT: Promise, Problems and Future Directions 2003.

3. Lave J and Wenger E. Situated Learning: Legitimate Peripheral Participation 1991.

\section{AFFILIATED INSTITUTIONS FOR CO-AUTHORS}

*Department of Mechanical Engineering, ETS

**Science and Humanities Education Service, ETS

***Department of Electrical Engineering, ETS 